\title{
Theoretical Study of Seed Movement in Cotton Seeds Selection Device
}

\author{
Obidov Avazbek, Sultonov Mirzaolim \\ Department Engineering and Technology, Namangan Institute of Engineering and Technology, Namangan, Uzbekistan \\ Email: aobidov@list.ru
}

How to cite this paper: Avazbek, O. and Mirzaolim, S. (2021) Theoretical Study of Seed Movement in Cotton Seeds Selection Device. Engineering, 13, 544-553. https://doi.org/10.4236/eng.2021.1310039

Received: August 27, 2021

Accepted: October 26, 2021

Published: October 29, 2021

Copyright $\odot 2021$ by author(s) and Scientific Research Publishing Inc. This work is licensed under the Creative Commons Attribution International License (CC BY 4.0).

http://creativecommons.org/licenses/by/4.0/

\begin{abstract}
The aim of the research work is to increase the yield of cotton fiber by improving the processing technology of germinated seeds, to improve the quality indicators of seeds and lint. In order to achieve this goal, a mesh surface device was created to sort the seeds into fractions. Sorting technology was developed on this device and operating modes were determined. In addition, the law of surface distribution of the fractions separated from the cotton stream moving along the surface of the net was determined, and based on the results of practical and theoretical research, a mode of sorting of cotton seeds was developed. As a result, differential equations of the law of oscillation of seeds on parallel bases, taking into account the angle of inclination for the movement of cotton seeds on the sorting surface, were constructed and programmed on a computer to construct the trajectory of seeds. On the basis of the laws of motion, the optimal value of the angle of inclination on the horizontal, which gives the state of sorting of seeds, as well as the values of the amplitude and frequency of vibrations, was determined.
\end{abstract}

\section{Keywords}

Cotton, Seeds, Slope Angle, Sorting Device, Fractions, Letuchka, Cotton Ginning, Amplitude, Frequency, Ginning, Sorting Sections, Brush Drum, Movement

\section{Introduction}

In recent years, the world market has been in demand by consumers for a certain range of cotton products and quality indicators. In this regard, the tasks for scientists and researchers in the field of primary processing of cotton are set for creation "smart" technologies which can control the quality and quantity of 
cotton products. In addition, current issues of the present period, there are several issues about separation of cotton fiber from seeds and increase of efficiency of processing of ginned seeds.

Scientists in the ginning industry face important tasks such as quality production without destroying cotton fiber, which is a valuable raw material for the textile and light industry. Loss of cotton fiber occurs mainly in the gin-linter section of the gin. In this area, fiber loss occurs due to the addition of fiber-containing seeds to other fibrous wastes.

The newly developed device is used when it is necessary to sort the seeds of raw cotton from the ginning process according to their fiber content. The use of this device prevents the addition of fiber, which is the main raw material of the textile industry, to the waste, lint. The amount of fiber output in the enterprise is increased due to the re-ginning of fibrous seeds or letuchka separated in the device and the separation of free fibers [1] [2] [3] [4] [5].

The addition of fiber, lint, or other fibrous waste, which is a valuable raw material, mainly occurs when seeds with poorly purified fiber coming from the genus are added to the cleaned seeds without being sorted at the required level. In the device offered by us, these shortcomings have been eliminated. In addition, the seeds are cleaned of various contaminants and the energy consumption of the enterprise is significantly reduced. That is, the seeds are divided into different fractions on the sorting surface, and fine impurities, clean ginned seeds, seeds prone to lintering fall into the grooves, respectively. Fibrous seeds that require re-ginning are sent to the ginning at the end of the process, where they are separated on the surface of a felt fabric made of hard yarn. As a result, the economic efficiency of the ginnery will increase significantly.

\section{Related Works}

It is known that cotton fiber plays an important role in the textile and light industries. This issue has been highlighted not only in modern research, but also in many scientific studies conducted in any period of the republic. The issue of increasing fiber output in the industry has always been relevant and remains relevant.

After the ginning process at the ginning plant, the cotton fibers are cleaned of various contaminants and sent for pressing. Demon seeds are sent to processes such as lintering, delintering, and from them fibrous products such as lint and short fibers are produced. Lintering and delintering of cotton seeds, i.e. the separation of fiber and short fiber remaining after seed germination, is extremely important as the main process. As a result of primary processing of seed cotton in ginneries, fiber, short fiber, seeds and technical seeds, feathers and plums are obtained.

The study mainly focuses on activities such as improving the quality of lint and preventing damage to demon-possessed seeds, while increasing the production of spinning fibers. 
In practice, the technological process of purification and regeneration is based on the principle of transferring the seed mixture from the process one or more times or from the regeneration machine until the material reaches the required state. In this way, labor costs, cleaning or regeneration costs increase. The quality of cleaning and regeneration in this process depends on the number of passes through this machine, and thus on how well the segregation mark of the seed mixture is selected and the mode of operation of the mechanical means and working bodies for its separation.

It is known that the following methods are used for separation [6] [7] [8]:

- separation by air flow;

- separation by mechanical means;

- material surface separation by difference;

- combined method.

\section{Materials and Methods}

The task is solved in the following way by placing a seed conductor grid on the starting part of the seed sorting device, which is in the form of continuous longitudinal grooves, the cross section of the surface of which is made of circular steel wire [9] [10].

The cotton seed cleaning and sorting device consists of the following (Figure 1): hopper feeder 1 , blade drum 2 , rubber limiter 3 , eccentric shafts 4 , belt drive 5 , electric motor 6 , wire sorting surface 7 , wire seed tray 8 , roller 10 mounted felt fabric (technical fabric made of hard yarn) 9, bearings 11, cylindrical barriers 12 that separate the sorting surface into sections, electric motor 13, belt drives 14, brush drum 15, fibrous seed and free fiber drop rod 16, residual compounds and trough for major contaminants 17.

The proposed device works as follows: after the ginning process, a mixture of various fine impurities and broken seeds, pure ginned seeds, lintering seeds, fibrous seeds (freewheels) and free fibers and large contaminants is sent to the hopper feeder 1 . The blade drum 2 performs the function of providing a flat in the bunker. From it, along with the seed sorting surface, a flat layer is sent to the seed sorting surface 7 made of wires by means of a rubber limiter 3 using a vibrating moving plate. The sorting surface 7 oscillates in conjunction with the eccentric shafts 4 , the belt drive 5 and the motor 6 , and the seed fractions coming into it pass through the holes of the columns depending on their size or fiber properties and fall into the bars 8 set for the seed fractions. For example, in the first section, separated by cylindrical barriers 12 , fine impurities, crushed seed residues, in the second section, fine-grained seeds, and in the third section, hairy seeds prone to lintering fall.

The next main process in the seed sorting device is the sorting of fibrous seeds or letuchka. To perform this task, the device is loaded on a special surface 9 made of felt fabric mounted on rollers 10.

It is known that the free fibers separated from the seeds during letting or 


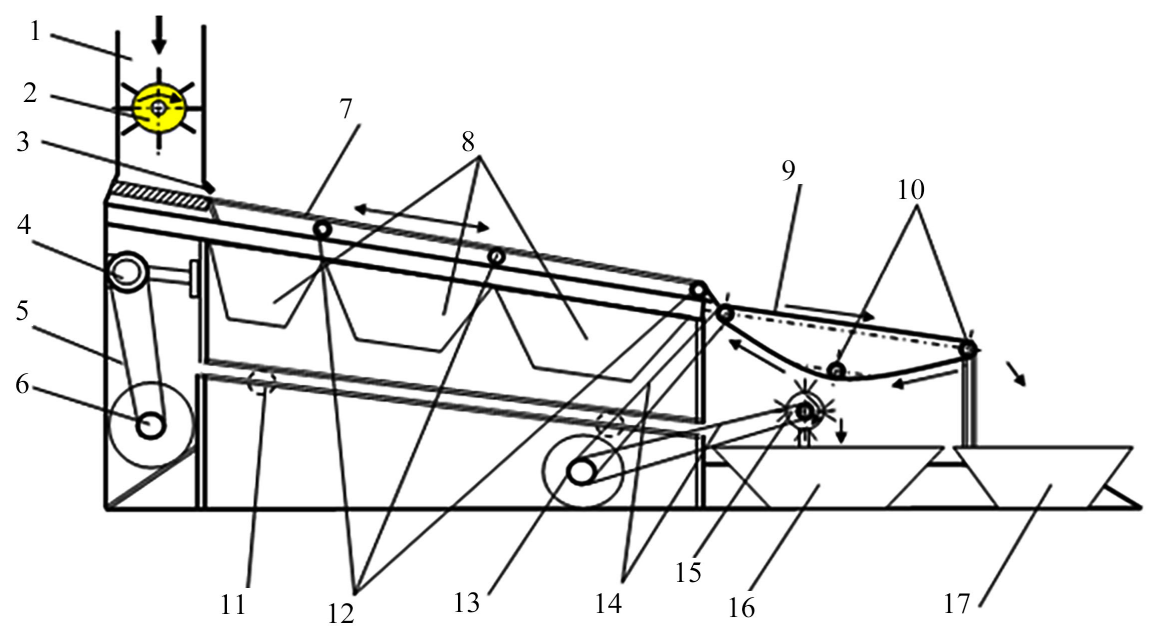

Figure 1. Schematics of a device for separating fibrous seeds.

ginning have a high adhesion to the fabric, so at the end of the process a special surface made of fabric was installed.

After the seeds pass through the third section, they contain mainly fibrous letuchka or free fibers, and in the next process they come to a special surface zone 9 of the felt fabric. Here, the fibrous seeds and free fibers in the seed fraction stick to the surface of the rotating fabric by means of rollers 10 , move along the surface and begin to fall under the influence of their own weight. The seeds, which are firmly attached to the surface of the fabric, are removed using a brush drum 15 mounted on the groove. Eventually the major contaminants and other contaminants remaining in the fraction fall into trough 17.

In this process, it is possible to increase the fiber output of the ginnery by $1 \%$ by sorting and re-sorting the separated fibrous seeds or letuchka. In addition, the working time of linters is reduced by removing $1 \%-2 \%$ of fine impurities in the seed mass, $3 \%-5 \%$ of pure ginned seeds. As a result, the consumption of electricity in the enterprise itself is significantly reduced.

Preparation of the cotton seed sorting device in the form of a continuous conductive surface consisting of continuous longitudinal wires ensures that the seed fractions can be easily placed along the grate, which prevents the cleaning of the net, interruptions during operation and sorting surface cracks with the processed product. At the same time the useful surface in the sorting of seed fractions increases by $90 \%$, in practice, so far the useful surface for sorting has reached $80 \%$ [11] [12].

The gaps between the wires were selected as a result of research. For example, the most widely used cotton variety today is S-6524, for which the crack spacing is $5 \mathrm{~mm}$ for fine impurities and broken seeds (first section), $7 \mathrm{~mm}$ for pure ginned seeds (second section), and for seeds prone to lintering (the third section) is adjusted to $9 \mathrm{~mm}$. The proposed device also allows you to easily change the distance of the section wires for other varieties of cotton seeds.

Thus, in the device for cleaning and sorting of cotton seeds it is possible to 
separate the mixture of ginned seeds into 5 fractions.

One of the main requirements for the current technological process of existing ginneries is to increase the efficiency of the seed production process and to develop and increase fiber yield while maintaining the natural properties of cotton fiber, which is a valuable raw material for the textile industry. It is also important to separate the cotton seed from various contaminants, broken and unripe seeds, to sort the mature seed, to check the fiber content of the cotton seed after the ginning process and to ensure that the fiber in the seed does not add to the waste. In other words, at present, in ginneries, various contaminants and unripe seeds are added to the composition of yellow seeds. In addition, well-cleaned seeds coming from the jinn are added to fiber-cleaned seeds and various other industrial wastes that have a degree of use in the textile industry. As a result, in the process of separating the fiber from the seed, the loss of fibers of sufficient length is observed.

Therefore, in order to overcome the above shortcomings in the study, the issues of new method of sorting technology for effective cleaning of cotton seeds from impurities and further fractionation were considered.

Let the seed be in relative motion with $O_{x}$ and $O_{y}$ in harmonic law (Figure 2 ). Seeds $o x$ and $o y$ in relative motion with the harmonic regularity (1) (Figure 2).

$$
\begin{aligned}
& \xi=a_{0} \sin (p t+\varepsilon) \\
& \eta=b_{0} \sin p t
\end{aligned}
$$

Affecting the seed fragment $o x$ and $o y$ forces in the direction:

$$
\left.\begin{array}{l}
X=P \sin \alpha+F_{1}(t)-T_{x} \\
Y=N-P \cos \alpha+F_{2}(t)+T_{y}
\end{array}\right\}
$$

Here:

$$
\left.\begin{array}{l}
F_{1}(t)=-m \ddot{\zeta}(t)=m a_{0} P^{2} \sin (p t+\varepsilon) \\
F_{1}(t)=-m \ddot{\eta}(t)=m b_{0} P^{2} \sin p t
\end{array}\right\}
$$

$P=m g:$ Gravity;

$T_{x}=f_{x} N, T_{y}=f_{y} \cdot P \sin \alpha$ : Frictional forces acting on the seed particle.

Differential equation of motion:

$$
\begin{aligned}
& \frac{\mathrm{d} V_{x}}{\mathrm{~d} t}=g \sin \alpha+p^{2} A \sin (p t+\varepsilon)-\frac{f_{x}}{m} N \\
& \frac{\mathrm{d} V_{y}}{\mathrm{~d} t}=\frac{N}{m}-g \cos \alpha+p^{2} B \sin p t+f_{y} g \cdot \sin \alpha
\end{aligned}
$$

Given that the oscillating motion occurs mainly in the direction of the base plane and that, the displacement of the seed particle in the direction perpendicular to the base is a small amount, that is $y \equiv 0$ in the condition $(4, \mathrm{~b})$ we find the expression for the compressive strength from equation: 


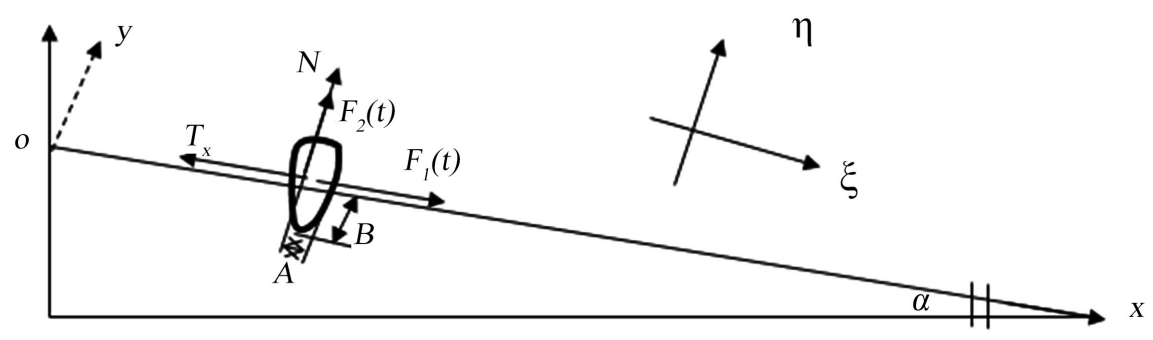

Figure 2. The movement of the seed in a harmonic law.

$$
N=m g \cos \alpha-m p^{2} B \sin p t-f_{y} m g \sin \alpha
$$

We clarify while Substituting $(5)$ into $(4, a)$ and then integrating once in time, the seed rate in the base direction $V_{x}$.

$$
V_{x}=\left[g \sin \alpha-f_{x} g\left(\cos \alpha-f_{y} \sin \alpha\right)\right] \cdot t-p a_{0} \cos (p t+\varepsilon)-p b_{0} \cos p t+C_{3}
$$

Prerequisite: $V_{x}(0)=0$ fixed amount:

$$
C_{3}=p\left(a_{0} \cos \varepsilon+b_{0}\right)
$$

Therefore, it is an expression of speed:

$$
\begin{aligned}
V_{x}= & {\left[g \sin \alpha-f_{x} g\left(\cos \alpha-f_{y} \sin \alpha\right)\right] \cdot t } \\
& -p\left[a_{0} \cos (p t+\varepsilon)+\cos p t\right]+p \cdot\left(a_{0} \cdot \cos \varepsilon+b_{0}\right)
\end{aligned}
$$

By integrating (6) once again in time, we determine the law of motion of the seed in the principal direction:

$$
\begin{aligned}
X(t)= & \frac{1}{2}\left[g \sin \alpha-f_{x} g\left(\cos \alpha-f_{y} \cdot \sin \alpha\right)\right] t^{2} \\
& -p^{2}\left(a_{0} \cdot \sin (p t+\varepsilon)+b_{0} \sin p t\right)+p\left(a_{0} \cos \varepsilon+b_{0}\right) t+C_{4}
\end{aligned}
$$

Prerequisite: $X(0)=0$ to $C_{4}=0$ as,

$$
\begin{gathered}
X(t)=\frac{1}{2}\left[g \sin \alpha-f_{x} g\left(\cos \alpha-f_{y} \cdot \sin \alpha\right)\right] t^{2} \\
+p\left(a_{0} \cdot \cos \varepsilon+b_{0}\right) t-p^{2}\left(a_{0} \sin (p t+\varepsilon)+b_{0} \sin p t\right) \\
X(t)=X_{1}(t)+X_{2}(t) \text { if we write: } \\
X_{1}(t)=\frac{1}{2}\left[g \sin \alpha-f_{x} g\left(\cos \alpha-f_{y} \cdot \sin \alpha\right)\right] t^{2}+p\left(a_{0} \cdot \cos \varepsilon+b_{0}\right) t \\
X_{2}(t)=-p^{2} a_{0} \cdot \sin (p t+\varepsilon)-p b_{0} \sin p t
\end{gathered}
$$

Hence, the complex motion of the seed is such that the relative motion (8) and (9) are the sum of the relative motions.

Using the formula (7) i.e. the oscillation motion of the seed along the $\mathrm{x}$ and $\mathrm{u}$ axes, a graph of the motion of the seed on the surface was constructed. In this study, the slope angle and amplitude were also varied and graphs of the most optimal options were given (Figure 3, Figure 4).

In these graphs, the uniform motion of the seed is the angle of inclination $\alpha=$ $13^{0}, \alpha=16^{0}$, vibration amplitude occurs in the case of $20 \mathrm{~mm}$. 


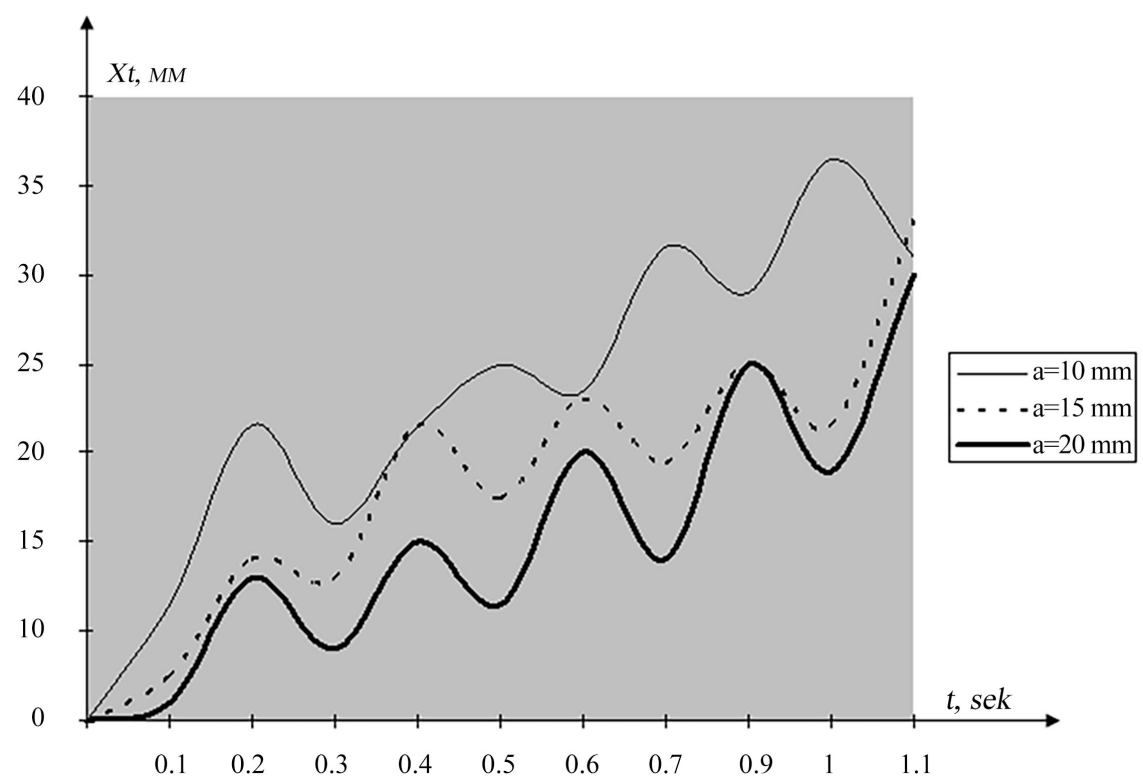

Figure 3. $\alpha=13^{0}$ in the movement of the seed over time.

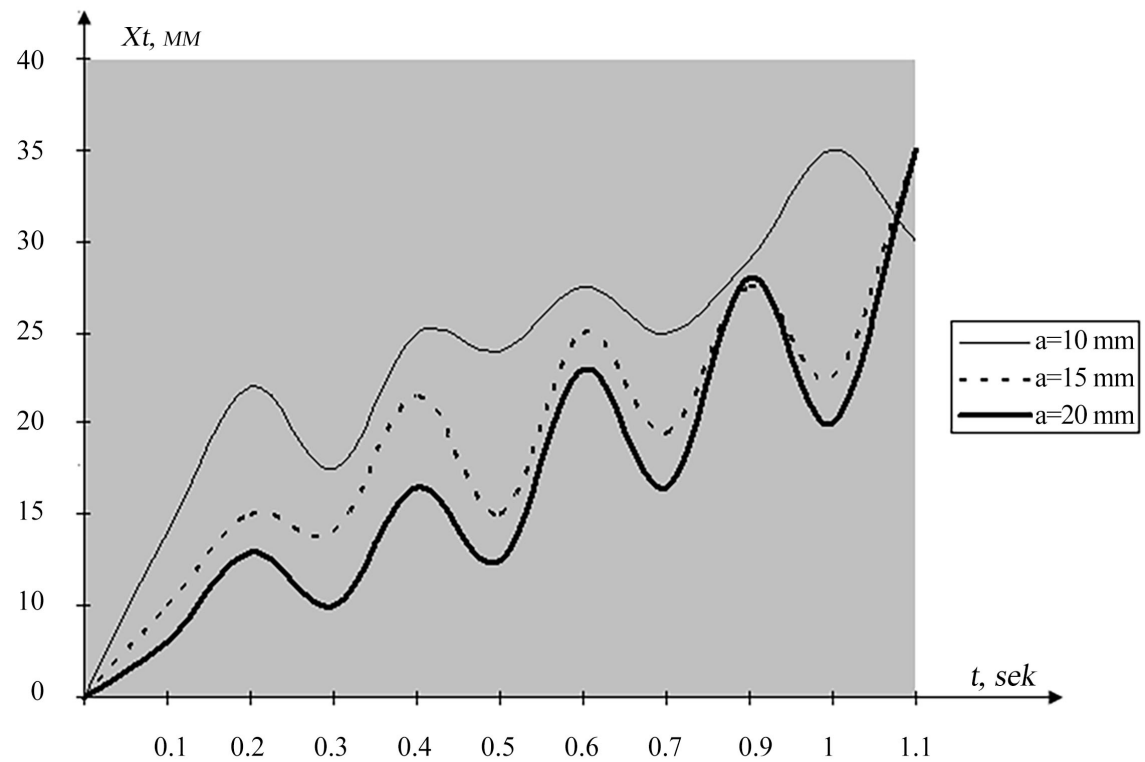

Figure 4. $\alpha=16^{0}$ in the movement of the seed over time.

\section{Calculation and Results}

The resulting equations make it possible to determine the length of each of the surface sections separated for fractions. In the study, each fraction was examined by varying the length of the surface section (section) from $50 \mathrm{~cm}$ to $70 \mathrm{~cm}$. At the initial surface part, the fine dirt and broken pieces of the seed mass should be separated, so that they should be separated at the set length. In the last surface part, a large volume of seed mass is separated, it is expedient to maximize the length of this part. Table 1 shows the spacing of the surface sections obtained as a result of the studies. 
Table 1. Lengths of surface parts to separate fractions.

\begin{tabular}{|c|c|c|c|c|c|}
\hline \multirow{2}{*}{$\begin{array}{l}\text { Number of surface } \\
\text { parts }\end{array}$} & \multicolumn{2}{|c|}{$1, \mathrm{sm}$} & \multirow{2}{*}{$V_{0,} \mathrm{~m} / \mathrm{s}$} & \multirow{2}{*}{$V, \mathrm{~m} / \mathrm{s}$} & \multirow{2}{*}{$f$} \\
\hline & Theor. & Practical & & & \\
\hline 1 & 69.8 & 70.0 & 0.225 & 0.24 & 0.591 \\
\hline 2 & 58.6 & 60.0 & 0.24 & 0.253 & 0.582 \\
\hline 3 & 64.0 & 70.0 & 0.25 & 0.261 & 0.575 \\
\hline
\end{tabular}

Table 2. The main parameters that affect the surface movement of cotton seeds.

\begin{tabular}{|c|c|c|c|c|c|}
\hline $\begin{array}{l}\text { Number of surfaces } \\
\text { for fractions }\end{array}$ & $a, \mathrm{~mm}$ & $p$, Hertz & $\alpha, \operatorname{grad}$ & $\mathrm{v}, \mathrm{m} / \mathrm{s}$ & $f$ \\
\hline \multirow{5}{*}{1} & & 6 & 14 & 0.21 & \multirow{5}{*}{0.59} \\
\hline & 15 & 7 & 14 & 0.25 & \\
\hline & & 8 & 13 & 0.24 & \\
\hline & \multirow{2}{*}{20} & 7 & 13 & 0.25 & \\
\hline & & 8 & 15 & 0.262 & \\
\hline \multirow{4}{*}{2} & & 5 & 15 & 0.215 & \multirow{4}{*}{0.582} \\
\hline & 15 & 7 & 13 & 0.23 & \\
\hline & \multirow[b]{2}{*}{20} & 7 & 15 & 0.265 & \\
\hline & & 8 & 15 & 0.266 & \\
\hline \multirow{5}{*}{3} & & 7 & 13 & 0.23 & \multirow{5}{*}{0.575} \\
\hline & 15 & 8 & 15 & 0.25 & \\
\hline & \multirow{3}{*}{20} & & & & \\
\hline & & 7 & 13 & 0.258 & \\
\hline & & 8 & 15 & 0.269 & \\
\hline
\end{tabular}

Optimal parameters were obtained as a result of additional research in scientific work and initial experiments in the work [13] [14] to ensure its efficiency in the operation of the device.

From the values shown in Table 2, which were determined on the basis of the study, it can be seen that the speed of movement of the seed to the end of the moving surface increases. This velocity varies in the parts of the surface allocated for the fractions. It should also be noted that the efficiency of the device (the fact that the fractions fall exactly in the grooves of the intended surfaces) also depends on the weight of the ginned seeds. In particular, in the first part of the surface, the weight and volume of the seed mass will be large and a longer surface spacing will be required.

\section{Conclusion of the Work}

In the study, taking into account the angle of inclination $\alpha$ for the movement of cotton seeds on the sorting surface, the differential equations of the law of vibrational motion of seeds on parallel bases were constructed and programmed on a computer, movements $x=x(t)$ and $y=y(t)$ based on graphs. Based on the 
laws of motion, it was substantiated that the angle of inclination along the horizontal, which gives the position of the seeds, is acceptable at a value of $13^{0}$. It was also found expedient to have amplitude of $18-20 \mathrm{~mm}$ and a frequency of 6 Gts.

\section{Conflicts of Interest}

The authors declare no conflicts of interest regarding the publication of this paper.

\section{References}

[1] Obidov, A., Akhmedhodjaev, K., Sarimsakov, O. and Holikov, Q. Investigation of the Properties of Fibrous Cotton Seeds, for Sorting on a Mesh Surface. Engineering, 10, 572-578. https://doi.org/10.4236/eng.2018.109041

[2] Obidov, A., Sultonov, M., Muhksinov, I. and Abdullaev, S. (2018) The Theoretical Studies of the Cultivation of Three Cotton Seeds along the Plain. Engineering, 10, 514-520.

[3] Lascano, R., Baumhardt, R., Goebel, T., Baker, J. and Gitz III, D. (2017) Irrigation Termination Thermal Time and Amount on Cotton Lint Yield and Fiber Quality. Open Journal of Soil Science, 7, 216-234. https://doi.org/10.4236/ojss.2017.79016

[4] Obidov, A.A. and Sultanov, M.M. (2020) To Research the Method of Separating Fibers Suitable for Spinning on a Needle Drum. International Scientific and Practical Conference Cutting Edge-Science, Shawnee, USA, 29-30 June 2020, 128-131.

[5] Obidov, A., Mamatqulov, O. and Sultanov, M. (2018) Theoretical Analysis of the Movement of Cotton Piece on the Slope Surface. International Conference Science and Practice: A New Level of Integration in the Modern World, Berlin-Warsawa, Vol. 82, 151-156.

[6] Axmedxodjayev, K., Umarov, A. and Ortiqova, A. (2019) Investigation of the Ginning Process on ДП Series Saw Gin Stands. Engineering, 11, Article ID: 94702. https://doi.org/10.4236/eng.2019.118036

[7] Obidov, A.A. (2006) Investigation of the Working Surface of a New Seeding Machine. Journal of Textile Problems, №2, 29-32.

[8] Obidov, A.A. (2007) Improvement of the Technology of Cleaning and Sorting of Ginned Seeds. Dissertation of Candidate of Technical Sciences. Tashkent: TITLI, $200 \mathrm{p}$.

[9] Sultonov, M. and Obidov, A. (2020) Investigation of Working Bodies of the Device for Separation of Fibers Suitable for Spinning from Cotton Waste. Engineering, 12, 893-905. https://doi.org/10.4236/eng.2020.1212063

[10] Korabayev, Sh.A., Matismailov, S.L., Yuldashev, A.T. and Atanbayev, D.D. (2020) Study of Fiber Movement outside the Crater of Pnevmomechanical Spinning Machine. Solid State Technology, 63, 3460-3466.

[11] Hamidov, S. and Obidov, A.A. (2020) About Economical Resource Stretching Tool Construction. International Scientific and Practical Conference Cutting Edge-Science, Shawnee, USA, 29-30 June 2020, 142-144.

[12] Korabayev, Sh.A., Mardonov, B.M., Matismailov, S.L. and Meliboyev, U.X. (2019) Determination of the Law of Motion of the Yarn in the Spin Intensifier. Engineering, 11, 300-306. https://doi.org/10.4236/eng.2019.115021

[13] Korabayev, Sh.A., Matismailov, S.L. and Salohiddinov, J.Z. (2018) Investigation of 
the Impact of the Rotation Frequency of the Discretizing Drum on the Physical and Mechanical Properties. Central Asian Problems of Modern Science and Education, 3, Article 9.

[14] Jahongir, A., Avazbek, O. and Muhiddin, V. (2021) Exploring the Efficiency of Experimental Construction of Sorting Ginned Cotton Seed Machine. Engineering, 13, 18-29. https://doi.org/10.4236/eng.2021.131002 